\title{
Situational and Dispositional Factors that Predict Motivation: a Multilevel Study
}

\author{
Heriberto Antonio Pineda-Espeje1 ${ }^{1}$, Jeanette López-Walle ${ }^{2}$ and Inés Tomás ${ }^{3}$ \\ 1 Universidad Autónoma de Baja California (Mexico) \\ 2 Universidad Autónoma de Nuevo León (Mexico) \\ ${ }^{3}$ Universitat de Valencia (Spain)
}

\begin{abstract}
This study aimed to test a multilevel mediation model which examined the relationship between the perceived motivational climate created by coaches at team level and motivational regulations towards sport at individual level, as mediated by individual goal orientations. 211 university athletes from 20 teams training in different types of sport completed a battery of instruments that measured the variables included in the model. The statistics significance level was .05. Results of the multilevel mediation model revealed that the task-involving climate at team level positively predicted individual task orientation $\left(\gamma_{01}=.77, p<.001\right)$ and autonomous motivation for sport practice $\left(\gamma_{01}=.68, p=.03\right)$. Task orientation positively predicts the autonomous motivation $\left(\gamma_{10}=.51, p<.01\right)$, and inversely the non motivation $\left(\gamma_{10}=-.76\right.$, $p<.001)$. Also task orientation partially mediated the relationship between task-involving climate and autonomous motivation $\left(\mathrm{b}_{1} \mathrm{~b}_{2}=.39 ; 95 \% \mathrm{CI}=[.11, .68] ; \tau=.68, p<.05\right)$, and fully mediated the relationship between task-involving climate and amotivation $\left(\mathrm{b}_{1} \mathrm{~b}_{2}=-.58 ; 95 \% \mathrm{CI}=[-.92,-.25] ; \tau=-.62, p>.05\right)$. The results are in line with previous research that have focused in the study of motivational climate at individual level, but the present study make a novel contribution by providing the perspective of a multilevel mediation model and thereby clarifying the phenomenon at team level.
\end{abstract}

Received 5 February 2016; Revised 2 February 2017; Accepted 6 February 2017

Keywords: goal orientations, self-determination, social context, sport, team level.

Motivation is an important topic for adherence towards sport and consequently for health, in young adults. Thus, knowing more about the antecedents of adaptive and maladaptive forms of motivation is important. Specifically, the possible nesting effect of the motivational climate at the team level is of interest and becomes the major contribution of this paper, as it has not been studied in previous literature. Concretely, this study aimed to test a multilevel mediation model which examined the relationships between the perceived motivational climate created by coaches at team level and motivational regulations toward sport at individual level, as mediated by individual goal orientations.

Correspondence concerning this article should be addressed to Heriberto Antonio Pineda-Espejel. Universidad Autónoma de Baja California. Av. Río Mocorito y Av. Monclova Exejido Coahuila. Mexicali. Baja California (Mexico).

E-mail: Antonio.pineda@uabc.edu.mx

We thank the Universitat de Valencia, particularly the Unidad de Investigación de Psicología del Deporte [Research Unit on Sport Psychology], directed by Dr. Isabel Balaguer, who is co-responsible for the project that supports this article, and we also thank the Instituto Universitario de Investigación en Psicología de los Recursos Humanos, del Desarrollo Organizacional y de la Calidad de Vida Laboral [University Research Institute on Psychology of Human Resources, Organizational Development and Quality of Working Life] (IDOCAL), led by Dr. José María Peiró, for lending the facilities used in the data collection and data analysis.
Within the theoretical frameworks of achievement goal theory (AGT; Ames, 1992; Nicholls, 1984; 1989) and self-determination theory (SDT; Deci \& Ryan, 1987; 2000), it has been established that both social (e.g., motivational climate) and personal (e.g., goal orientations or dispositional goals) variables act as determinants of intrinsic motivation. On one hand the AGT (Ames, 1992; Nicholls, $1984 ; 1989)$ posits that in achievement contexts such as sport, individuals develop a series of behavioral and cognitive processes to achieve their goals and demonstrate competence; moreover, this competence or skill is defined differently depending on developmental and individual differences that are influenced by dispositional and situational factors. Thus, two of AGT's main constructs are goal orientation and motivational climate.

Goal orientation - the manner in which individuals define competence - can be self-referenced (task orientation) or referenced by others (ego orientation). In this sense, individuals who are predominantly task-oriented feel successful by learning something new or improving their skills, whereas ego-oriented individuals feel successful by attaining superiority over others (Nicholls, 1989).

Biddle (2001) posited that individual differences regarding goal orientation might be influenced by the environment. In studying the environment, AGT 
incorporates the motivational climate, which includes those situational goals that are set in an achievement context (Ames, 1992) and that are created by others who are significant to the person. Several authors have considered that the coach of a sport team is one of the most influential people in athletes' sporting experience based in the environment that he or she creates within the team (e.g., Bartholomew, Ntoumanis, \& ThogersenNtoumani, 2010).

According to AGT, there are two types of motivational climates known as task-involving and ego-involving climates. A task-involving climate is distinguished by private recognition based on one's own progress and an assessment based on individual improvement. This approach considers that mistakes are a natural part of the improvement process. An ego-involving climate includes public recognition that depends on social comparisons as the basis on which to judge success and considers mistakes as something to avoid (Ames, 1995).

Previous studies have tested the relationship between motivational climates and goal orientations in sport, considering motivational climates at the individual level. Empirical evidence has shown that task orientation is positively associated with a task-involving climate (e.g., Moreno, Cervelló, \& González-Cutré, 2007; 2008; Pineda, López-Walle, \& Medina, 2011; Reyes, 2009; Sánchez et al., 2009) and that an ego-involving climate is positively related to ego orientation (e.g., Balaguer, Castillo, Duda, \& García-Merita, 2011; Moreno et al., 2007; 2008). Although other studies have not supported that last association (e.g., Pineda et al., 2011; Reyes, 2009; Sánchez et al., 2009).

On the one hand, AGT examines how perceptions of motivational climate created by significant others (e.g., coach) interact with the dispositional goals to influence behavior in achievement contexts, so the goals are developmentally acquired through the social learning and identification process; on the other hand, the SDT analyzes how social conditions address the inherent self-actualization tendencies that either support or thwart behavioral internalization. Both theories have very different philosophical starting points (e.g., social-cognitive vs. organismic), however Ryan and Deci (1989) argued that each theory focuses on distinct bodies of ideas and insights that can be considered complementary rather than contradictory. So the frameworks can be used together to extract additional information regarding motivational processes, although they cannot in themselves be integrated for the same ends. Following this recommendation, recent empirical research has combined AGT and SDT to examine motivational environments in relation to athlete motivation (Smith et al., 2016) and physical activity (Fenton, Duda, Appleton, \& Barrett, 2016).
With regard to motivation, SDT considers that the basic dichotomy of intrinsic/extrinsic motivation is insufficient, based on the level of self-determined behaviour. Moreover, SDT suggests that intrinsic motivation is not the only case of self-determined activity and that extrinsically motivated behavior can be either autonomous (self-determined) or controlled (Deci \& Ryan, 1987). Deci and Ryan (2000) suggested a continuum of four extrinsic motivational regulations with a varying degree of determination that would involve the following (from highest to lowest self-determination): 1) integrated regulation, when the behavior is consistent with other values and the needs of the individual; 2) identified regulation, where the person identifies with an activity and gives value to it; 3 ) introjected regulation, a regulatory process within the person that is experienced as a demand or pressure; and finally, 4) external regulation, which refers to those behaviors controlled by external sources. Based on this reasoning, Deci and Ryan (1991) suggested that integrated and identified regulations can be considered as autonomous forms of motivation; meanwhile introjected and external regulations can be considered as controlled ones.

Autonomous motivation is perceived as intentional behavior that is based on the values and interests of a particular individual who experiences volition for actions, selects the results to pursue and chooses how to achieve them; it is also characterized by integration and the absence of pressure and conflict (Deci \& Ryan, 1991). Therefore, autonomous motivation is composed by the combination of intrinsic motivation, integrated regulation, and identified regulation. By contrast, in controlled motivation, internal and/or external pressure and external control guide behavior (Deci \& Ryan, 1991); thus, it is composed by the combination of introjected regulation and extrinsic motivation. Finally, amotivation refers to the lack of intention to act.

According to Duda (2001), motivational responses in sport are shaped by the coach's creation of a particular motivational climate. In addition, dispositional factors are also important to the study of self-motivation. Personal processes such as goal orientations are included within dispositional factors (Deci \& Ryan, 1987). A specific line of research in AGT has examined the relationship of goal orientation and/or perceptions of the motivational climate, with motivation (Standage, Duda, \& Ntoumanis, 2003).

In the physical education context, Brunel (1999) found that task orientation is positively related with intrinsic motivation - whereas ego orientation is positively related with external and introjected regulations (forms of controlled motivation) - and that a taskinvolving climate is positively correlated with autonomous forms of motivation. Other studies have shown that task orientation positively predicts autonomous 
forms of motivation (intrinsic motivation and identified regulation) (e.g., Ntoumanis, 2001; Standage et al., 2003) and negatively predicts amotivation (e.g., Standage et al., 2003), whereas ego orientation is positively related with intrinsic motivation (e.g., Standage et al., 2003). In the sport context, positive relationship has been found between ego-involving climate and identified regulation (autonomous form of motivation) (Moreno et al., 2007), and proxy variables of autonomous motivation as dedication (Curran, Hill, Hall, \& Jowett, 2015). Meanwhile, the task-involving climate was positively related to autonomous forms of motivation (Smith, Cumming, \& Smoll, 2008), and proxy variables as dedication, enthusiasm (Curran et al., 2015), and enjoyment (Jaakkola, Ntoumanis, \& Liukkonen, 2016).

Newton and Duda (1999) reported that sport research has traditionally used regression analysis to examine the interaction between goal orientations and motivational climates (at the individual level) and their further effects on behavioral variables. In this line, previous research has examined the independent contribution of motivational climate - or the interaction between goal orientation and motivational climate - to explain autonomous motivation, operationalizing motivational climate at the individual level (the level of the athlete's perception of the climate created by the coach), but not at the team (the level of the perception of the team). The individual approach helps to understand how the athletes' individual perception of interpersonal coaching styles influences motivational regulations toward sport. However, we cannot directly assume that the relationship that has been found at the individual level will also take place at the team level (Duda, 2001). It is therefore necessary to study the nesting effect of the motivational climate at the team level, as it has not been addressed in the previous literature. The team level approach attempts to understand how a specific climate created in a team and perceived and shared by its different players influences motivational regulations. In this regard, it is important to remark that climate can be defined as the shared perceptions of members of a team or group (Anderson \& West, 1998). Testing motivational climate at the team level implies considering the fact that athletes belonging to the same team have the same coach, so they will have similar situational experiences that will be distinct from the experiences of other teams. Thus, testing motivational climate at the team level allows capturing how belonging to a team influences social and cognitive factors. To address these issues, Raudenbush and Bryk (2002) proposed the use of hierarchical linear models to help assess the effects of both individual and team variables.

Therefore, the present study aimed to test a multilevel mediation model that analyzed the effects of contextual (perceived motivational climate created by coaches at team level) and dispositional (goal orientations at individual level) factors on motivational regulations towards sport at individual level. Concretely, the model tested the mediator role of individual goal orientations (task and ego) in the relationship between team motivational climate (task-involving and egoinvolving) and individual motivational regulations towards sport (autonomous, controlled and amotivation). According to previous literature that has analyzed relationship at the individual level, we expected to find empirical support for the hypothesized relationships in the proposed model (see Figure 1).

\section{Method}

\section{Participants}

The study sample included 211 Mexican college athletes of both genders (115 women and 96 men), belonging to 20 teams training in different sporting disciplines (e.g., athletics, basketball, handball, baseball, football, weightlifting, swimming). Participants aged between 17 and 28 years old $(M=19.97$ years, $S D=2.01)$, with an average time spent practicing the sport of 6.3 years $(S D=3.02)$, and an average seniority with the team coach of 2.1 years $(S D=1.01)$.

\section{Instruments}

The perceived motivational climate created by the coach was measured using the Perceived Motivational Climate in Sport Questionnaire (PMCSQ-2), as adapted to the Mexican context (López-Walle, Balaguer, Castillo, \& Tristán, 2011). This questionnaire consists of 24 items, 11 of which measure the perceived task-involving climate (e.g., "Athletes help one another learn"), and the other 13 measure the perceived ego-involving climate (e.g., "The coach only congratulates athletes when they stand out from others"). The questions were answered using a five-point Likert-type scale ranging from never (1) to always (5).

Individual trends on goal orientations in sport were measured with the Task and Ego Orientation in Sport Questionnaire (TEOSQ), as adapted to the Mexican context (López-Walle, Balaguer, Meliá, Castillo, \& Tristán, 2011). This questionnaire consists of 13 items

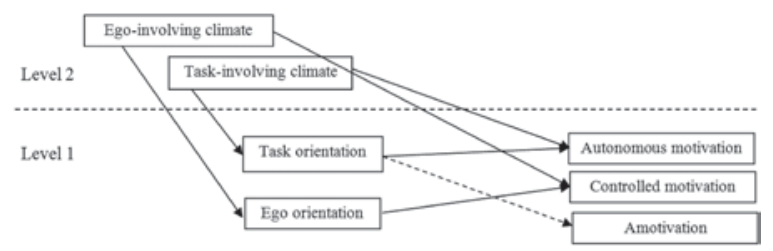

Figure 1. Hypothesized multilevel mediation model. Note: The solid lines express positive relationships and the dashed lines express negative relationships. 
and is divided into two scales that measure task orientation using seven items (e.g., "I am more successful in my sport when I learn a new exercise, and it makes me want to practice more") and ego orientation using six items (e.g., "I am more successful in my sport when I am the only one who is able to do the play or who has that skill"). The questions were answered using a fivepoint Likert-type scale ranging from strongly disagree (1) to strongly agree (5).

Motivational regulations were measured with the Spanish version (Balaguer, Castillo, \& Duda, 2007) of the Sport Motivation Scale (SMS), which consists of 28 items that can be grouped into three factors, consistent with SDT (Deci \& Ryan, 2000) and with previous studies (e.g., Vansteenkiste, Zhou, Lens, \& Soenens, 2005). Thus, autonomous motivation was assessed by asking athletes to indicate whether they practiced sport for intrinsic (e.g., "For the pleasure of learning new training techniques") or identified reasons (e.g., "Because it is one of the best ways of developing other aspects of myself"). To assess controlled motivation, athletes were asked to indicate whether they practiced sport for introjected (e.g., "Because I need to engage in sport to feel good about myself") or external reasons (e.g., "Because of the prestige of being an athlete"). A similar procedure was followed to assess amotivation (e.g., "I'm not sure, but I feel that I am unable be successful in this sport"). The questions were answered using a seven-point Likert-type scale ranging from does not correspond at all (1) to corresponds exactly (7). In this investigation, autonomous motivation was the average resulting from intrinsic motivation and identified regulation, and controlled motivation was the average resulting from external and introjected regulation.

\section{Procedure}

The present research was conducted in accordance with international ethical guidelines that are consistent with American Psychological Association (APA) guidelines. Ethical approval for the study was obtained from a university ethics review committee. Personal contact was first made with team coaches to inform them about the project. Instruments were applied during a training session in which the main researcher was present to give instructions and answer athletes' questions. Emphasis was placed on the confidentiality of athletes' individual responses as well as on the need to answer honestly. In addition, the researcher explained to them that responding to the questionnaires implied voluntarily accepting to participate in the research.

\section{Data analysis}

Descriptive statistics (mean and standard deviation) and scale reliability (Cronbach's $\alpha$ coefficient) were also calculated for all variables employed in the study using SPSS 19.0. The hypothesized relationships in the proposed multilevel mediation model were estimated using hierarchical linear modeling (HLM; Raudenbush \& Bryk, 2002) with the PRELIS application of LISREL 8.80. This analysis strategy assumes a hierarchical structure for the data, it allows for the consideration of the influence of variables operationalized at the team-level (level 2) on variables at the individual level (level 1). In the sport context, athletes belong to different teams, and a different coach leads each team. This grouping tends to promote uniformity within the team, which naturally violates the assumption that data corresponding to athletes constitute independent observations. The multilevel hierarchical analysis allows for consideration of nested structure in connection with the data collected from athletes from multiple teams.

Before testing the hypothesized multilevel mediation model, aggregation of team members' scores for task-involving climate and ego-involving climate was justified in SPSS. Therefore, it was necessary to assess within-team agreement, and between-team discrimination (Chan, 1998). Within-team agreement was assessed using the average deviation index (ADI; Dunlap, Burke, \& Smith-Crowe, 2003), taking the criterion established by Dunlap and colleagues (2003) of $\mathrm{ADI}<\mathrm{c} / 6$ (where $\mathrm{c}$ is the number of categories in the response scale) as a reference for interpretation. In addition, analysis of variance (ANOVA) was used to test between-team discrimination on perceived taskinvolving and ego-involving climates.

Following the recommendations discussed in the previous literature (e.g., Zhang, Zyphur, \& Preacher, 2009), the independent variables were centered. Individual variables (task orientation and ego orientation) were centered at their group mean; team-level variables (task-involving climate and ego-involving climate) were centered at their grand mean.

According to Zhang and colleagues (2009), the model tested in the present research (see Figure 1) would be a 2-1-1 multilevel mediation model, in which a teamlevel variable influences an individual-level variable, which in turn has an effect on another variable at the individual level. The sequence of hierarchical linear models used to estimate the relationships hypothesized in the model is detailed below: (1) one-way ANOVA models (baseline model with random intercepts) to estimate intra-team and inter-team variance for the dependent variables at the individual level (goal orientations and motivational regulations), calculating at the same time the intraclass correlation coefficient (ICC). The presence of inter-team differences validates the inference that the data present a hierarchical structure, thus pointing to the logic in developing 
hierarchical linear models (Heck \& Thomas, 2000). (2) Intercepts-as-outcome models to test the cross-level effects of team-level predictors (task-involving climate and ego-involving climate) on mediator variables (task orientation and ego orientation) at the individual level.

(3) Random regression coefficients models to estimate the effects of individual level predictors (task orientation and ego orientation) on outcome variables at the individual level (autonomous motivation, controlled motivation and amotivation). This model allows to estimate variances for intercepts and slopes of regression across teams and to estimate the proportion of variance explained by predictors at the individual level. Finally, (4) when the results of the previous analysis indicated a multilevel mediation effect, an additional intercepts-as-outcome model was tested. In this model, the effect of the team-level predictor $(\mathrm{X})$ on the outcome variable $(\mathrm{Y})$ was included, in addition to the effect of the individual predictor (the mediating variable, M) on the corresponding outcome variable $(Y)$. This last effect represents the direct or nonmediated effect $(\tau)$ of $X$ on $Y$, thus offering information regarding whether there was total or partial mediation.

Finally, the product-of-coefficients test proposed by Taylor, Mackinnon, and Tein (2008) was used to confirm the detected effects of mediation. The effect of mediation is estimated using the $(\alpha \beta)$ product, where $(\alpha)$ represents the effect of the team-level predictor $(X)$ on the mediating variable $(\mathrm{M})$ or individual-level predictor, and $(\beta)$ represents the effect of the mediating variable $(\mathrm{M})$ on the outcome variable at the individual level (Y), controlling for the effect of X on Y. A 95\% confidence interval for the mediation effect $(\alpha \beta)$ can be estimated by adding or subtracting 1.96 times the standard error (where 1.96 is the critical value for the normal distribution, and the standard error was the Sobel (1982) multivariate delta standard error). If the estimated confidence interval does not include zero, the mediation effect is confirmed.

\section{Results}

\section{Descriptive statistics}

The descriptive statistics, reliability (Cronbach's $\alpha$ ), and the correlations between the study variables are shown in Table 1. Internal consistency in all the scales was acceptable as Cronbach's alpha was above the criterion of .70 determined for psychological scales (Nunnally, 1978). Motivational climates were positively related to goal orientations in their respective dimensions. Autonomous motivation was positively correlated with task-involving climate and task orientation. Amotivation was negatively related to taskinvolving climate and goal orientation. Additionally, autonomous motivation was positively related to controlled motivation.

\section{Multilevel analysis}

Before aggregating team members' scores for the team level variables, within-team agreement and between team discrimination was tested. The average ADI values for task-involving and ego-involving climates were $.60(S D=0.15)$ and $.72(S D=0.16)$, respectively. Both values were below the criterion of .83 for Likert scales with 5 response categories $(5 / 6=.83)$, which suggested the existence of shared perceptions within the team regarding task-involving and ego-involving climates. Additionally, ANOVA results indicated adequate discrimination between teams for both taskinvolving $(F(19,191)=2.69, p<.01)$ and ego-involving climates $(F(19,191)=2.24, p<.01)$. Based on these results, we concluded that aggregating team members' scores for task-involving and ego-involving climates was justified.

Regarding HLM results, one-way ANOVA models carried out showed no significant between-groups differences for task orientation $\left(\tau_{00}=.44, p=.36\right.$; ICC $=.02)$ and ego orientation $\left(\tau_{00}=.67, p=.30\right.$; ICC $=.04)$. For this reason, additional analyses with SPSS were run to explore variance among teams for the goal

Table 1. Descriptive statistics, Pearson product-moment correlation coefficient between study variables and the reliability of measurement scales

\begin{tabular}{|c|c|c|c|c|c|c|c|c|c|c|}
\hline & Range & $M$ & $S D$ & 1 & 2 & 3 & 4 & 5 & 6 & 7 \\
\hline 1 Task Climate & $1-5$ & 4.00 & 0.60 & $(.83)$ & & & & & & \\
\hline 2 Ego Climate & $1-5$ & 2.43 & 0.66 & $-.25^{* *}$ & $(.84)$ & & & & & \\
\hline 3 Task orientation & $1-5$ & 4.21 & 0.68 & $.53^{* *}$ & $-.18^{* *}$ & $(.82)$ & & & & \\
\hline 4 Ego orientation & $1-5$ & 2.81 & 0.84 & -.06 & $.20^{* *}$ & $.19^{* *}$ & (.83) & & & \\
\hline 5 Autonomous motivation & $1-7$ & 5.51 & 1.01 & $.41^{* *}$ & -.05 & $.34^{* *}$ & .01 & $(.90)$ & & \\
\hline 6 Controlled motivation & $1-7$ & 4.49 & 1.28 & .08 & .07 & .08 & .13 & $.56^{* *}$ & $(.80)$ & \\
\hline 7 Amotivation & $1-7$ & 2.50 & 1.43 & $-.28 * *$ & .15 & $-.35^{* *}$ & .04 & -.03 & $.29^{* *}$ & $(.71)$ \\
\hline
\end{tabular}

Note: ${ }^{*} p<.05 ;{ }^{* *} p<.01$. The value in parentheses represents the Cronbach's alpha coefficient for each scale. 
orientations measures. The ANOVA results showed statistically significant differences between teams for ego orientation $(F(19,191)=1.66, p=.04)$, and marginally significant differences for task orientation $(F(19,191)=1.50, p=.08)$. Based on these results, we decided to keep both goal orientation dimensions and continue with the next multilevel model. The ICC values for task orientation and ego orientation indicated that $2 \%$ and $4 \%$ of the variance in these variables was due to differences between teams, respectively.

The intercepts-as-outcome models introduced the perceived motivational climate (task-involving and ego-involving climate) as predictor of the corresponding individual-level goal orientation (task orientation and ego orientation). Results showed that only task-involving climate at team-level was significantly associated with individual task orientation $\left(\gamma_{01}=.77, p<.001\right)$.

One-way ANOVA models for motivational regulations did not exhibit significant differences for autonomous motivation $\left(\tau_{00}=.97, p=.32\right.$; ICC $\left.=.05\right)$, controlled motivation $\left(\tau_{00}=1.67, p=.29\right.$; ICC $\left.=.02\right)$ or amotivation $\left(\tau_{00}=1.99, p=.35\right.$; ICC $\left.=.02\right)$. The random regression coefficients models showed that task orientation positively predicted autonomous motivation $\left(\gamma_{10}=.51, p<.01\right)$ and negatively predicted amotivation $\left(\gamma_{10}=-.76\right.$, $p<.001)$. The intercepts-as-outcome models - nested in the previous models after controlling for the teamlevel effects of motivational climate on motivational regulations - showed that task-involving climate had a positive effect on autonomous motivation $\left(\gamma_{01}=.68\right.$, $p=.03$ ). Figure 2 displays the relationships and parameters that were shown to be significant. Table 2 displays all parameters for the different tested models.

Based on the previous results, two multilevel mediation effects were detected. Task orientation partially mediated the relationship between team perceptions of task-involving climate and individual autonomous motivation $\left(\mathrm{b}_{1} \mathrm{~b}_{2}=.39 ; 95 \% \mathrm{CI}=[.11, .68]\right.$; $\tau=.68, p<.05)$, and totally mediated the relationship between team perceptions of task-involving climate and individual amotivation $\left(\mathrm{b}_{1} \mathrm{~b}_{2}=-.58 ; 95 \% \mathrm{CI}=\right.$ $[-.92,-.25] ; \tau=-.62, p>.05)$.

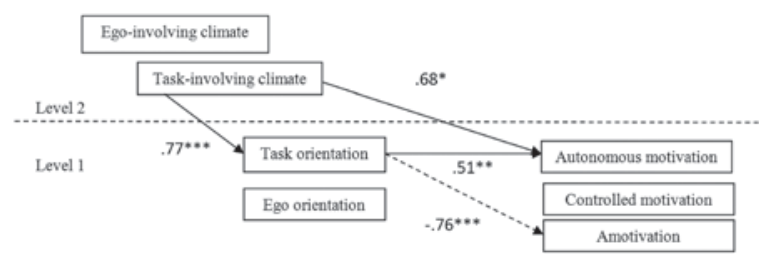

Figure 2. Multilevel mediation model of the relationships between motivational climate (team level), goal orientations and motivational regulations (individual level).

Note: ${ }^{* * *} p<.001 ;{ }^{* *} p<.01 ;{ }^{*} p<.05$.

\section{Discussion}

In this study, we tested the effects of team perceptions of motivational climates (task-involving and egoinvolving) on athletes' individual goal orientations (task and ego), and in turn on their individual motivational regulations (autonomous, controlled and amotivation) using hierarchical linear modeling analysis. The adding value of the study was testing motivational climate at the team level which allowed us to analyze the top-down influence of team-level constructs (perceived motivational climate created by coaches) on individual-level constructs (goal orientations and motivational regulations towards sport) and also examine multilevel relationships.

Results partially confirm the relationships hypothesized in the proposed multilevel mediation model (see Figure 1). Team perceived task-involving climate created by the coach had a positive direct effect on autonomous motivation for sport practice, as well as a positive indirect effect through task orientation. In other words, task orientation partially mediated the relationship between the team perceived task-involving climate created by the coach and autonomous motivation towards sport. Also, task orientation completely mediated the relationship between task-involving climate and amotivation towards sport.

According to the theoretical assumptions of the AGT (Ames, 1992; Nicholls, 1984; 1989), the above results suggest that when members of a sport team perceive that the coach emphasizes learning, emphasizes improving and mastering of exercises, considers mistakes to be part of the learning process, and appreciates their effort, they will feel successful (competent or skilled) in their sport when learning or mastering an exercise. All the aforementioned is in line with results of previous studies that analyzed the relationship between climate at the individual level and goal orientations (e.g., Moreno et al., 2007; 2008; Pineda et al., 2011; Reyes, 2009; Sánchez et al., 2009).

According to the principles of the SDT (Deci \& Ryan, $1987 ; 2000)$, the results of this study suggest that when athletes judge their competence using self-referenced criteria, they participate in their sport because they have freely chosen to do so - based on their interest in the activity itself, the enjoyment triggered by training, or because they identify with the sport -by giving it value or importance. This is consistent with the empirical results of Deci and Ryan (2000) and Reeve (1989), which found that task orientation is positively correlated with autonomous motivation. The explanation for this is that task orientation involves a less external or evaluative perspective that allows individuals to focus on an activity to improve tasks and acquire mastery (Deci \& Ryan, 2000; Nicholls, 1984); furthermore 
Table 2. Multilevel hierarchical analysis: motivational climate, goal orientations and motivational regulations

\begin{tabular}{|c|c|c|c|c|c|c|}
\hline \multirow[b]{2}{*}{ Level/Variable } & \multicolumn{3}{|c|}{ Random regression coefficients model } & \multicolumn{3}{|c|}{ Intercepts-as-outcome model } \\
\hline & Parameter & SE & $Z$ & Parameter & SE & $Z$ \\
\hline \multicolumn{7}{|l|}{ Task orientation } \\
\hline \multicolumn{7}{|l|}{ Team } \\
\hline$\overline{\text { Task-involving Climate }}$ & & & & .77 & .17 & $4.30^{* * *}$ \\
\hline Deviance/df & & & & $521.87 / 5$ & & \\
\hline \multicolumn{7}{|l|}{ Ego orientation } \\
\hline (intercept) & & & & 2.80 & .06 & $41^{* * *}$ \\
\hline \multicolumn{7}{|l|}{ Team } \\
\hline$\overline{\text { Ego-involving Climate }}$ & & & & .22 & .25 & .89 \\
\hline Deviance/df & & & & $418.64 / 5$ & & \\
\hline \multicolumn{7}{|l|}{ Autonomous Motivation } \\
\hline (intercept) & & & & 5.51 & .08 & $66.88^{* * *}$ \\
\hline \multicolumn{7}{|l|}{ Individual } \\
\hline Task orientation & .36 & 0.01 & .91 & .51 & .15 & $3.42^{* * *}$ \\
\hline \multicolumn{7}{|l|}{ Team } \\
\hline$\overline{\text { Task-involving Climate }}$ & & & & .68 & .29 & $2.36^{*}$ \\
\hline Deviance/df & & & & $571.67 / 12$ & & \\
\hline \multicolumn{7}{|l|}{ Controlled motivation } \\
\hline (intercept) & & & & 4.50 & .09 & $47.23^{* * *}$ \\
\hline \multicolumn{7}{|l|}{ Individual } \\
\hline Ego orientation & & & & .18 & .11 & 1.64 \\
\hline \multicolumn{7}{|l|}{ Team } \\
\hline$\overline{\text { Ego-involving Climate }}$ & & & & .04 & .35 & .12 \\
\hline Deviance/df & & & & $693.50 / 12$ & & \\
\hline \multicolumn{7}{|l|}{ Amotivation } \\
\hline$\overline{\text { (intercept) }}$ & & & & 2.50 & .09 & $26.53^{* * *}$ \\
\hline \multicolumn{7}{|l|}{ Individual } \\
\hline Task orientation & & & & -.76 & .15 & $-5.01^{* * *}$ \\
\hline Deviance/df & & & & $720.43 / 12$ & & \\
\hline
\end{tabular}

Note: ${ }^{* * *} p<.001 ;{ }^{* *} p<.01 ;{ }^{*} p<.05 . \mathrm{SE}=$ standard error. Variables in bold letters in the first column represent de dependent variable for each model.

task orientation is experienced as an end in itself, therefore, it is more likely to be regulated by self-determined reasons (Deci \& Ryan, 1987). All that supports the suggestion made by Duda (2001) that subjects' usage of criteria under their personal control contributes to developing a sense of autonomy.

Additionally, results of this study indicate that when the team perceives a task-involving climate generated by the coach, that facilitates athletes defining themselves as competent individuals when they are learning or mastering an exercise, and additionally, that will prevent them from attending training with no motivation. It should be noted that the effect of task-involving climate on amotivation is in accordance with results of previous studies in sport and physical education contexts in which motivational climate has been considered at the individual level (e.g., Balaguer et al., 2011; Moreno et al., 2007; Standage et al, 2003).
Also, when the team perceive that the coach appreciates the athletes' efforts and focuses on learning the exercises, this directly facilitates that athletes perceive themselves as initiators of their own conduct and responsible for it; in this manner, athletes experience the volition to act. Thus, sport participants find the activity interesting and enjoy it, which eliminates the need to work out based on extrinsic reasons. This result ensues because the task-involving climate is less coercive and favors athletes' active involvement in the training process, and awareness of their own performance. This finding offers empirical support in the sport context to the notion proposed by Deci and Ryan (1987) that autonomous motivation must come from oneself and is therefore facilitated only by contextual events (situational variables). Also reinforces the results of approximations of previous studies at the sport and physical education contexts that measured motivational 
climate at the individual level (e.g., Balaguer et al., 2011; Brunel, 1999; Curran et al., 2015; Jaakkola et al., 2016; Smith et al., 2008; Standage et al., 2003).

However, our results do not support the relationship between team perceptions regarding the ego-involving climate created by a coach and athletes' ego orientation. This result contradicts empirical evidence from previous studies that have analyzed the motivational climate perceived by athletes at the individual level (e.g., Balaguer et al., 2011; Curran et al., 2015; Moreno et al., 2007; 2008), but is consistent with other studies that have also evaluated the climate at the individual level (e.g., Pineda et al., 2011; Reyes, 2009; Sánchez et al., 2009). This finding also suggests that relationships built at the individual level do not automatically emerge at the team-level.

The multilevel mediation approach employed in this study enabled to consider the group nature of the motivational climate created by a coach on a sport team, which has led to a new understanding of the predictors of motivational regulations in sport and to the effects of situational predictors and dispositional factors, in particular. Although past studies had evaluated the effects of the social context on motivational regulations through motivational climate (e.g., Brunel, 1999; Moreno et al., 2007; Ntoumanis, 2001; Standage et al., 2003), these evaluations were undertaken on the basis of the perceptions of each athlete separately. The present work replicates these results, but considering climate as shared perceptions of the members of a team.

Among the findings of this study, it is showed that autonomous motivation and controlled motivation are positively related. In this regard, Judge, Bono, Erez, and Locke (2005) indicated that both motivations do not seem to be negatively related. Moreover, recent research has highlighted that individuals can report high levels of both motivation types (e.g., Healy, Ntoumanis, \& Duda, 2016; Langan et al., 2015), which is in line with the results of the present study.

As theoretical implications, this paper gives another methodological approach in favor of better understanding of the reality of the phenomenon, bearing in mind that athletes belong to teams and are trained by the same coach, and that teams may provide athletes with unique experiences linked to schemes, training approaches and social norms. From the practical point of view, the results suggest that for coaches to encourage training for volitional reasons - without resorting to imputing feelings of obligation and incompetence - it is necessary to plan a variety of exercises or tasks for training sessions that encourage teamwork during training sessions and that consider mistakes as part of the learning process. In addition, when evaluating athletes, their learning, effort and mastery of technical skills and tactics should be considered and this assessment should be based on the improvement of personal marks and on relying on objectives that respect the principle of individuality of training.

Simultaneously, there are some limitations concerning the size and specific characteristics of the sample used in this study. First, we are aware about the small sample size (20 teams). Furthermore, we also assume that the results of the study can be influenced by the competitive level of the sample, and thus we must be cautious about its generalizability to other samples of athletes. However, these limitations indicate possible directions for future research. There is no doubt that continuous efforts are required to engage in research that adopts the SDT approach to deepen base knowledge regarding athletes' social experiences, so that we encourage developing future research on this topic using study samples with different competition levels and greater number of teams.

Another important limitation of the study points to its design, as the use of a cross-sectional design does not enable to arrive to strong conclusions on the temporal ordering of the variables. With this in mind, it is important that future research adopt a longitudinal data approach, in light of the possibility that athlete motivation influences coach behaviors. Longitudinal designs are presumed to offer good opportunities to add further to our understanding for the causal process in the phenomena of interest.

In conclusion, this study extends the existing sportscientific literature and takes into consideration both the individual and the team perspectives. The present research has provided a new perspective to better understand the contextual and dispositional factors that predict motivational regulations from a different methodological approach. This study adds to previous studies that have employed a traditional methodological approach, deepening the understanding of the influence of team level situational and individual dispositional factors on motivational regulations in sport. Therefore, when analyzing the motivational climate from a multilevel perspective, the relationship between the motivational climate and goal orientations is replicated in task dimensions, but not in ego dimensions. Furthermore, empirical evidence has been provided which indicates that task orientation has a partial mediating role between task-involving climate and autonomous motivation towards sport practice, and a total mediating role in the relationship between taskinvolving climate and amotivation.

\section{References}

Ames C. (1992). Classrooms: Goals, structures and student motivation. Journal of Educational Psychology, 84, 261-271. https:/ / doi.org/10.1037/0022-0663.84.3.261 
Ames C. (1995). Achievement goals, motivational climate, and motivational processes. In G. Roberts (Ed.), Motivation in sports and exercise (pp. 197-214). Champaign, IL: Human Kinetics Books.

Anderson N. R., \& West M. A. (1998). Measuring climate for work group innovation: Development and validation of the team climate inventory. Journal of Organizational Behavior, 19, 235-258. https://doi.org/10.1002/(SICI)10991379(199805)19:3<235::AID-JOB837>3.0.CO;2-C

Balaguer I., Castillo I., \& Duda J. L. (2007). Propiedades psicométricas de la escala de motivación deportiva en deportistas españoles [Psychometric properties of the scale of sports motivation in Spanish athletes]. Revista Mexicana de Psicología, 24, 197-207.

Balaguer I., Castillo I., Duda J., \& García-Merita M. (2011). Asociaciones entre la percepción del clima motivacional creado por el entrenador, orientaciones disposicionales de meta, regulaciones motivacionales y vitalidad subjetiva en jóvenes jugadoras de tenis [Associations between the perception of motivational climate created by coaches, dispositional goal orientations, forms of self-regulation and subjective vitality in young tennis players]. Revista de Psicología del Deporte, 20, 133-148.

Bartholomew K. J., Ntoumanis N., \& Thøgersen-Ntoumani C. (2010). The controlling interpersonal style in a coaching context: Development and initial validation of a psychometric scale. Journal of Sport and Exercise Psychology, 32, 193-216. https: / /doi.org/10.1123/jsep.32.2.193

Biddle S. J. H. (2001). Enhancing motivation in physical education. In G. C. Roberts (Ed.), Advances in motivation in sport and exercise (pp. 101-127). Champaign, IL: Human Kinetics.

Brunel P. C. (1999). Relationship between achievement goal orientations and perceived motivational climate on intrinsic motivation. Scandinavian Journal of Medicine and Science in Sports, 9, 365-374. https: / / doi.org/10.1111/ j.1600-0838.1999.tb00258.x

Chan D. (1998). Functional relations among constructs in the same content domain at different levels of analysis: A typology of composition models. Journal of Applied Psychology, 83, 234-246. https:/ / doi.org/10.1037/ 0021-9010.83.2.234

Curran T., Hill A. P., Hall H. K., \& Jowett G. E. (2015). Relationships between the coach-created motivational climate and athlete engagement in youth sport. Journal of Sport and Exercise Psychology, 37, 193-198. https://doi. org/10.1123/jsep.2014-0203

Deci E. L., \& Ryan R. M. (1987). The support of autonomy and the control of behavior. Journal of Personality and Social Psychology, 53, 1024-1037. https:/ / doi.org/10.1037/ 0022-3514.53.6.1024

Deci E. L., \& Ryan R. M. (1991). A motivational approach to self: Integration in personality. In R. Dienstbier (Ed.), Nebraska symposium on motivation: Vol. 38. Perspectives on motivation (pp. 237-288). Lincoln, NE: University of Nebraska Press.

Deci E. L., \& Ryan R. M. (2000). The "what" and "why" of goal pursuits: Human needs and the self-determination of behavior. Psychological Inquiry, 11, 227-268. https: / / doi. org/10.1207/S15327965PLI1104_01
Duda J. L. (2001). Goal perspective research in sport: Pushing the boundaries and clarifying some misunderstandings. In G. C. Roberts (Ed.), Advances in motivation in sport and exercise (pp. 129-182). Champaign, IL: Human Kinetics.

Dunlap W. P., Burke M. J., \& Smith-Crowe K. (2003). Accurate test of statistical significance for $r W G$ and average deviation interrater agreement indexes. Journal of Applied Psychology, 88, 356-362. https://doi. org/10.1037/0021-9010.88.2.356

Fenton S. A. M., Duda J. L., Appleton P. R., \& Barrett T. G. (2016). Empowering youth sport environments: Implications for daily moderate-to-vigorous physical activity and adiposity. Journal of Sport and Health Science. https:/ / doi.org/10.1016/j.jshs.2016.03.006

Healy L. C., Ntoumanis N., \& Duda J. L. (2016). Goal motives and multiple-goal striving in sport and academia: A person-centered investigation of goal motives and inter-goal relations. Journal of Science \& Medicine in Sport, https:/ / doi.org/10.1016/j.jsams.2016.03.001

Heck R. H., \& Thomas S. L. (2000). An introduction to multilevel modeling techniques. Mahwah, NJ: Lawrence Erlbaum Associates, Inc.

Jaakkola T., Ntoumanis N., \& Liukkonen J. (2016). Motivational climate, goal orientation, perceived sport ability, and enjoyment within Finnish junior ice hockey players. Scandinavian Journal of Medicine E Science in Sports, 26, 109-115. https://doi.org/10.1111/sms.12410

Judge T. A., Bono J. E., Erez A., \& Locke E. A. (2005). Core self-evaluations and job and life satisfaction: The role of self-concordance and goal attainment. Journal of Applied Psychology, 90, 257-268. https:/ / doi.org/10.1037/ 0021-9010.90.2.257

Langan E., Hodge K., McGowan S., Carney S., Saunders V., \& Lonsdale C. (2016). The influence of controlled motivation alongside autonomous motivation: Maladaptive, buffering, or additive effects? International Journal of Sport and Exercise Psychology, 14, 57-71. https:/ /doi.org/ 10.1080/1612197x.2015.1016084

López-Walle J., Balaguer I., Castillo I., \& Tristán J. (2011). Clima motivacional percibido, motivación autodeterminada y autoestima en jóvenes deportistas mexicanos [Perceived motivational climate, selfdetermined motivation and self-esteem in young Mexican athletes]. Revista de Psicología del Deporte, 20, 209-222.

López-Walle J., Balaguer I., Meliá J. L., Castillo I., \& Tristán J. (2011). Adaptación a la población mexicana del Cuestionario de Orientación al Ego y a la Tarea en el Deporte [Task and Ego Orientation in Sport Questionnaire (TEOSQ) Adapted to Mexican population]. Revista de Psicología del Deporte, 20, 523-536.

Moreno J. A., Cervelló E., \& González-Cutré D. (2007). Analizando la motivación en el deporte: Un estudio a través de la teoría de la autodeterminación [Analyzing motivation in sport: A study using self-determination theory]. Apuntes de Psicología, 25, 35-51.

Moreno J. A., Cervelló E., \& González-Cutré D. (2008). Relationships among goal orientations, motivational climate and flow in adolescent athletes: Differences by gender. The Spanish Journal of Psychology, 11, 181-191. https://doi.org/10.1017/S1138741600004224 
Newton M., \& Duda J. L. (1999). The interaction of motivational climate, dispositional goal orientations, and perceived ability in predicting indices of motivation. International Journal of Sport Psychology, 30, 63-82.

Nicholls J. G. (1984). Conceptions of ability and achievement motivation. In R. Ames \& C. Ames (Eds.), Research on motivation in education: Student motivation (Vol. I., pp. 39-73). New York, NY: Academic Press.

Nicholls J. G. (1989). The competitive ethos and democratic education. Cambridge, MA: Harvard University.

Ntoumanis N. (2001). A self-determination approach to the understanding of motivation in physical education. British Journal of Educational Psychology, 71, 225-242. https: / / doi.org/10.1348/000709901158497

Nunnally J. C. (1978). Psychometric theory. New York, NY: McGraw-Hill.

Pineda A., López-Walle J., \& Medina M. (2011). Clima motivacional y orientación de metas en clavadistas juveniles mexicanos [Motivational climate and goal orientation in young Mexican divers]. Revista de Ciencias del Ejercicio FOD, 6, 4-7.

Raudenbush S. W., \& Bryk A. S. (2002). Hierarchical linear models: Applications and data analysis methods. Dewbury Park, CA: Sage.

Reeve J. (1989). The interest-enjoyment distinction in intrinsic motivation. Motivation and Emotion, 13, 83-103. https:/ / doi.org/10.1007/BF00992956

Reyes M. A. (2009). Clima motivacional y orientación de meta en futbolistas peruanos de primera división [Motivational climate and goal orientation in Peruvian first division football players]. Cuadernos de Psicología del Deporte, 9, 5-20.

Ryan R. M., \& Deci E. L. (1989). Bridging the research traditions of task/ego involvement and Intrinsic/Extrinsic motivation: Comment on Butler (1987). British Journal of Educational Psychology, 81, 265-268. https://doi.org/ 10.1037/0022-0663.81.2.265
Sánchez P., Leo F., Gómez F., Sánchez D., Cruz E., \& García T. (2009). Orientaciones de metas y clima motivacionales de los otros significativos en jóvenes de jugadores extremeños de balonmano [Goal orientations and motivational climate of the other significatives in young handball players from Extremadura]. Retos, 16, 22-27.

Smith R. E., Cumming S. P., \& Smoll F. L. (2008). Development and validation of the Motivational Climate Scale for Youth sports. Journal of Applied Sport Psychology, 20, 116-136. https:/ / doi.org/10.1080/10413200701790558

Smith N., Tessier D., Tzioumakis Y., Fabra P., Quested E., Appleton P., ... Duda. J. L. (2016). The relationship between observed and perceived assessments of the coach-created motivational environment and links to athlete motivation. Psychology of Sport \& Exercise, 23, 51-63. https://doi.org/10.1016/j.psychsport.2015.11.001

Sobel M. E. (1982). Asymptotic confidence intervals for indirect effects in structural equation models. Sociological Methodology, 13, 290-312. https://doi.org/10.2307/270723

Standage M., Duda J. L., \& Ntoumanis N. (2003). A model of contextual motivation in physical education: Using constructs from self-determination and achievement goal theories to predict physical activity intentions. Journal of Educational Psychology, 95, 97-110. https:/ / doi.org/ 10.1037/0022-0663.95.1.97

Taylor A. B., MacKinnon D. P., \& Tein J. Y. (2008). Tests of the three-path mediated effect. Organizational Research Methods, 11, 241-269. https://doi.org/10.1177/1094428107300344

Vansteenkiste M., Zhou M., Lens W., \& Soenens B. (2005). Experiences of autonomy and control among Chinese learners: Vitalizing of immobilizing? Journal of Educational Psychology, 97, 468-483. https://doi.org/10.1037/ 0022-0663.97.3.468

Zhang Z., Zyphur M. J., \& Preacher K. J. (2009). Testing multilevel mediation using hierarchical linear models: Problems and solutions. Organizational Research Methods, 12, 695-719. https://doi.org/10.1177/1094428108327450 